\title{
EFFECT OF HEMOLYSIN PRODUCED BY VIBRIO PARAHAEMOLYTICUS ON MEMBRANE CON- DUCTANCE AND MECHANICAL TENSION OF RABBIT MYOCARDIUM
}

\author{
Issei Seyama, Hiroshi IrIsawa, Takeshi Honda,* \\ Yoshifumi TAKEDA,* and Toshio Minatani* \\ Department of Physiology, School of Medicine, Hiroshima \\ University, Hiroshima 734, Japan \\ *Institute for Microbial Disease, Osaka University, \\ Suita, Osaka 565, Japan
}

\begin{abstract}
The mechanisms of the action of hemolysin extracted from Vibrio parahaemolyticus in the S-A node and right atrium cells of rabbit were studied by means of the single sucrose gap and isometric tension recording methods. Hemolysin caused the membrane to depolarize reversibly without affecting the action potential generating mechanism. Lowering of $\left[\mathrm{Na}^{+}\right]_{0}$ inhibited membrane depolarization in the presence of hemolysin while the readmission of normal Tyrode solution induced depolarization. Tetrodotoxin (TTX) barely antagonized the depolarizing action of hemolysin but slowed the rate of development of depolarization. Therefore, this depolarization is considered to be primarily due to the increase in conductance to Na which TTX may not block. The dose-response relationship was obtained by measuring a change in membrane resistance. The concentration necessary to yield one-half of the maximum reduction of the membrane resistance was determined to be $7.5 \mu \mathrm{g} / \mathrm{ml}$.

Accumulation of $\mathrm{Na}$ within the cell may be responsible for an increase of twitch tension observed during the action of a low concentration of hemolysin. On the other hand, a higher concentration of hemolysin seemed to promote exchange of intracellular $\mathrm{Na}$ with extracellular $\mathrm{Ca}$, especially when the $\mathrm{Na}$ concentration of the perfusing solution was reduced, and led to stronger contracture.
\end{abstract}

The unique Na-channel blocking action of Tetrodotoxin (TTX) stimulated studies of other drugs as potential tools for the study of excitable membranes

Received for publication October 6, 1976

瀬山一正, 入沢 宏, 本田武司, 竹田美文, 三輪谷俊夫 
(NARAHASHI, 1974). A series of toxins have been discovered mostly by their profound action on nerves, skeletal muscles and myocardiums (GoTo et al., 1967; Ulbricht, 1969; Hogan and Albuquerque, 1971; Narahashi and Seyama, 1974). Recently, marked cardiotoxicity was observed in purified, thermostable, direct hemolysin produced by Vibrio parahaemolyticus (HoNDA et al., 1976a; Goshima et al., 1976). Spontaneous activity of cultured mouse heart cells and of in situ rat heart cells ceased on application of hemolysin. Evidence now shows that low doses of hemolysin directly affects the heart cell membrane and causes reduction of the maximum diastolic potential as well as the amplitude of the action potentials in cultured myocardial cells (Honde et al., 1976a; GosHIMA et al., 1976). The aim of this experiment is to elucidate the mechanism of action of hemolysin in cardiac cells, based on the conductance change of the membrane.

\section{METHODS}

Preparations. The right atrium, including the sino-atrial (S-A) node region, was isolated from albino rabbits weighing 2-2.5 $\mathrm{kg}$ under sodium pentobarbital anesthesia $(20 \mathrm{mg} / \mathrm{kg})$. The $\mathrm{S}-\mathrm{A}$ node region was removed from the rest of the atrium by cutting along the crista terminalis. In order to measure the slope conductance of the membrane, the single sucrose gap method, described previously (NomA and IRISAWA, 1974; SeYama, 1976), was used. Man-made strand preparations of the S-A node were prepared by dissecting them along the direction perpendicular to the crista terminalis (SEYAMA, 1976). Similar atrial preparations were made by isolating a trabecula from the right atrium. Since they retain a cable property, the change in membrane resistance could be obtained as the square root of the measured deflection of electrotonic potential on the preparations.

Electrophysiological measurements. A conventional $3 \mathrm{M} \mathrm{KCl}$ microelectrode having a resistance of approximately 20-50 M $\Omega$ and high input impedance operational amplifier (Analog Device, $603 \mathrm{~K}$ ) were used for recording the transmembrane potential of a cardiac cell. The output of the operational amplifier was displayed on an oscilloscope and a strip chart recorder. The output was also differentiated with a condenser and resistor-coupled circuit having a time constant of $0.1 \mathrm{msec}$. The latter was used for measurement of the maximum rate of rise of action potential.

Mechanical tension recording. Strands of the atrial trabecula were suspended in a bath and one end of the muscle was connected to a strain gauge while the other end was fixed to the bottom of the bath. The isometric tension and its first derivative were displayed on a strip chart recorder.

Solutions. A Tyrode solution containing (in $\mathrm{mM}$ ) $\mathrm{NaCl}, 136.9 ; \mathrm{KCl}, 2.7$; $\mathrm{CaCl}_{2}, 1.8 ; \mathrm{MgCl}_{2}, 0.5 ; \mathrm{NaH}_{2} \mathrm{PO}_{4}, 1.5$; and $\mathrm{Na}_{2} \mathrm{HPO}_{4}, 4.5$ with a $\mathrm{pH}$ of 7.4 was used in the present experiment. In preparing solutions of various Na concentra- 
tions, $\mathrm{NaCl}$ was replaced with Tris chloride on a mole-for-mole basis. The temperature of the perfusates, aerated with pure $\mathrm{O}_{2}$, was maintained at $37^{\circ} \mathrm{C}$ throughout the experiments. The rate of perfusion was $2-3 \mathrm{ml} / \mathrm{min}$. TTX was used in crystalline form (Sankyo Co., Tokyo). Inderal ${ }^{\circledR}$ (I.C.I. Pharmaceutical Division, England) propranolol hydrochloride was employed.

Isolation and purification of the $V$. parahaemolyticus toxin (Thermostable direct hemolysin). Thermostable direct hemolysin was isolated from the culture filtrate of $V$. parahaemolyticus WP-1 as described previously (HoNDA et al., 1976b). The strain was cultured in medium containing $30 \mathrm{~g}$ of $\mathrm{NaCl}, 10 \mathrm{~g}$ of peptone (Difco), $5 \mathrm{~g}$ of $\mathrm{Na}_{2} \mathrm{HPO}_{4}$ and $5 \mathrm{~g}$ of glucose per liter of distilled water at $\mathrm{pH}$ 7.67.8. After incubating the cells at $37^{\circ} \mathrm{C}$ for about $15 \mathrm{hr}$ with shaking, the culture filtrate was collected by centrifugation. Solid $\left(\mathrm{NH}_{4}\right)_{2} \mathrm{SO}_{4}(35.1 \mathrm{~g} / 100 \mathrm{ml})$ was added to the culture filtrate, and the resultant precipitate was dissolved in a small volume of $0.01 \mathrm{M}$ phosphate buffer $\left(\mathrm{Na}_{2} \mathrm{HPO}_{4}-\mathrm{KH}_{2} \mathrm{PO}_{4}, \mathrm{pH} 7.0\right)$. It was then dialyzed against the same buffer and used as a crude toxin.

The crude toxin was purified by successive DEAE-cellulose, hydroxylapatite and Sephadex G-200 column chromatography according to the detailed procedures described elsewhere (Honde et al., 1976b). The purified toxin is a protein having a molecular weight of about 42,000 ; its homogeneity was demonstrated by sodium dodecyl sulfate-polyacrylamide gel disc electrophoresis and analytical ultracentrifugation.

\section{RESULTS}

Action of hemolysin on the $S$-A node cell

A typical experiment of the effect of $2.5 \mu \mathrm{g} / \mathrm{ml}$ hemolysin on the action potential of the S-A node is illustrated in Fig. 1. During the application of hemolysin, reduction of the overshoot and the maximum diastolic potential were observed. Spontaneous activity ceased within $10 \mathrm{~min}$ but the resting membrane continued to depolarize. The threshold dose for cessation of the spontaneous activity in a total 20 experiments, was $1.0 \mu \mathrm{g} / \mathrm{ml}$. In three preparations where the continuous observations were successful, it took 7-24 min (mean $13 \mathrm{~min}$ ) to suspend spontaneous activity with $1 \mu \mathrm{g} / \mathrm{ml}$. With $5 \mu \mathrm{g} / \mathrm{ml}$ of hemolysin, it took 2-16 min (mean $5.2 \mathrm{~min}$ in five preparations). It was frequently observed that a single application of $1 \mu \mathrm{g} / \mathrm{ml}$ of hemolysin was ineffective in suspending spontaneous activity but repeated applications of this dose resulted in elimination of spontaneous activity within 7-8 min. Thus, it is possible that the hemolysin effect is accumulative. After treatment with $2 \mu \mathrm{g} / \mathrm{ml}$ of hemolysin, a wash out period of 20-30 min was necessary to resume the spontaneous activity in Tyrode solution. Recovery was extremely slow when the preparations were perfused with higher concentrations of hemolysin $(>10 \mu \mathrm{g} / \mathrm{ml})$ for $5 \mathrm{~min}$. In one preparation, spontaneous activity ceased within $1.5 \mathrm{~min}$ after application of $20 \mu \mathrm{g} / \mathrm{ml}$ 


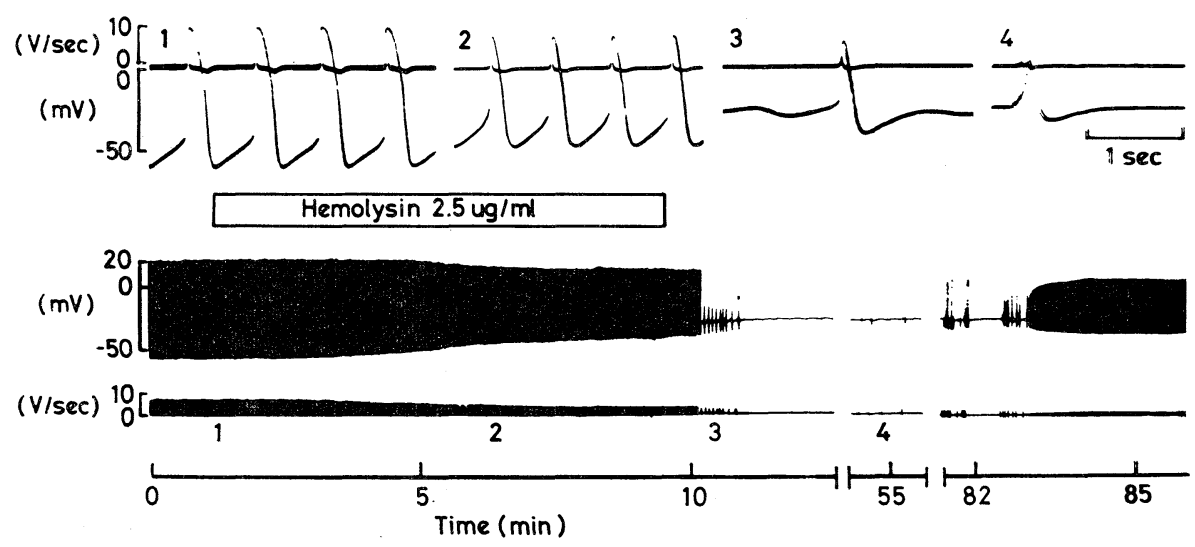

Fig. 1. Effect of hemolysin $(2.5 \mu \mathrm{g} / \mathrm{ml})$ on the action potential of the S-A node. Fast speed original action potentials are given in the upper row. The reference line shows both zero membrane potential and maximum rate of rise of action potential. The action potential shown in panel 4 was elicited by a single electrical shock. Continuous tracings of the change of action potential and maximum rate of rise of action potential in response to $2.5 \mu \mathrm{g} / \mathrm{ml}$ hemolysin are shown in the lower row. Numerals on the upper row correspond to the recorded time of the action potentials on the lower row.

of hemolysin, but resumption of activity required at least $2 \mathrm{hr}$ after return to normal Tyrode solution. Approximately $55 \mathrm{~min}$ after cessation of the spontaneous activity, electrical stimulation elicited an action potential with a low rising rate, small amplitude and small after-hyperpolarization (Fig. 1-4). During the hemolysin-induced depolarization of the membrane, changes in the membrane resistance were measured in a quiescent S-A node preparation by applying constant anodal current pulses (Fig. 2). Accompanying depolarization, membrane resistance was reduced by $20 \%$, indicating increased permeability of the membrane. The action potential elicited as an anodal break excitation (Figs. 2-2 and 3) showed a smaller after-hyperpolarization with concomitant reduction of membrane resistance.

\section{Effect of hemolysin on the atrial myocardium}

The reduction of the maximum rate of rise of action potential and the resting potential as well as shortening of the action potential duration were observed after administration of $2.5 \mu \mathrm{g} / \mathrm{ml}$ of hemolysin on the right atrial trabecula (Fig. 3). For recovery from hemolysin action, about 50 min washing with normal Tyrode solution was necessary.

In order to examine the effect of hemolysin on the action potential generating mechanism, it is necessary to compare the action potentials elicited from equal membrane potentials. In this experiment the resting potential in Tyrode solution decreased from $-44 \mathrm{mV}$ to $-36 \mathrm{mV}$ after applying $5 \mu \mathrm{g} / \mathrm{ml}$ of hemolysin (Fig. 4). When the take-off potentials were held at $-100 \mathrm{mV}$ by application of anodal pulses, there was essentially no change in the pattern of action potential and the maximum 


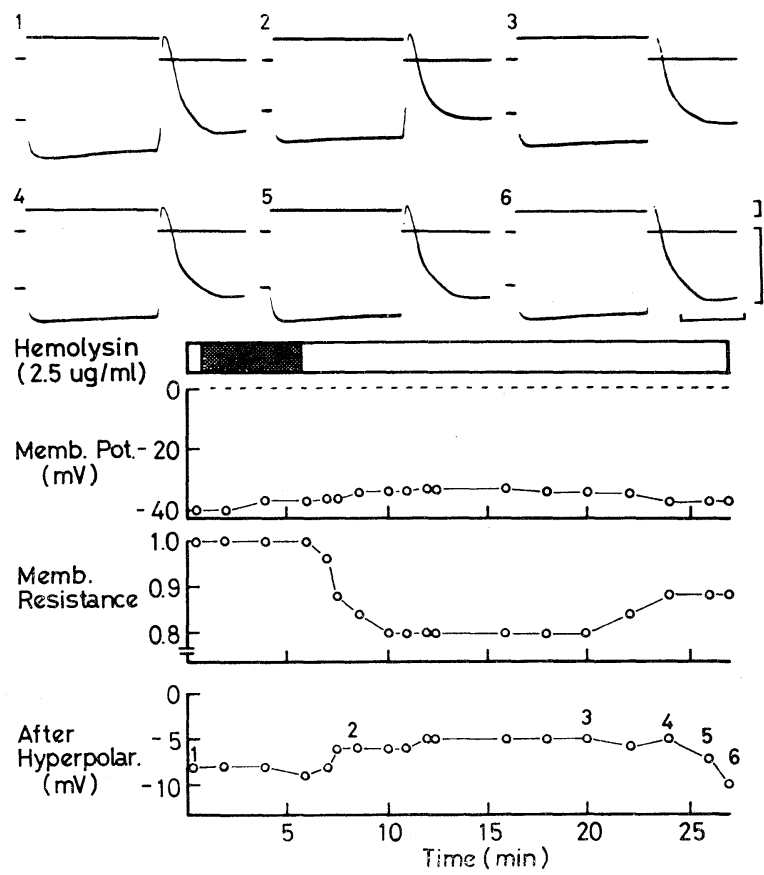

Fig. 2. Changes in the membrane resistance of a quiescent S-A node cell. In the right corner of panel 6 , the upper vertical bar represents $5 \times 10^{-5} \mathrm{~A}$, lower vertical bar $50 \mathrm{mV}$ and horizontal bar $500 \mathrm{msec}$. Panels 1 through 6 were recorded during the time course indicated by the numerals 1 to 6 in the bottom graph, respectively. Upward deflection of the applied current indicates the anodal pulse. The magnitude of after-hyperpolarization (bottom graph) was measured as a difference from the resting potential. The direction for increasing the negativity is taken as negative. The application of hemolysin is indicated by the shaded area.

rate of rise of action potential. Therefore, it is thought that hemolysin at this concentration can depolarize the membrane without affecting the action potential generating mechanism.

\section{Changes of membrane conductance in low Na Tyrode solution}

The foregoing results suggest that the action of hemolysin might be caused either by a non-selective increase in membrane conductance or by a specific increase in membrane conductance to Na. To further clarify the mechanism of action of hemolysin, a study of the effect of removing $\mathrm{Na}$ from the external medium was carried out. However, it is known that the Na-Ca exchange mechanism works extensively in Na-free medium (REUTER and SEITZ, 1968), whereby the reduction of membrane resistance may be produced through an increase of potassium conductance. To minimize this effect, $30 \% \mathrm{Na}$ Tyrode $\left(43 \mathrm{~mm}\left[\mathrm{Na}^{+}\right]_{\mathrm{o}}\right)$ was chosen as the low $\mathrm{Na}$ medium. Constant current pulses of $1 \times 10^{-5} \mathrm{~A}$ were 


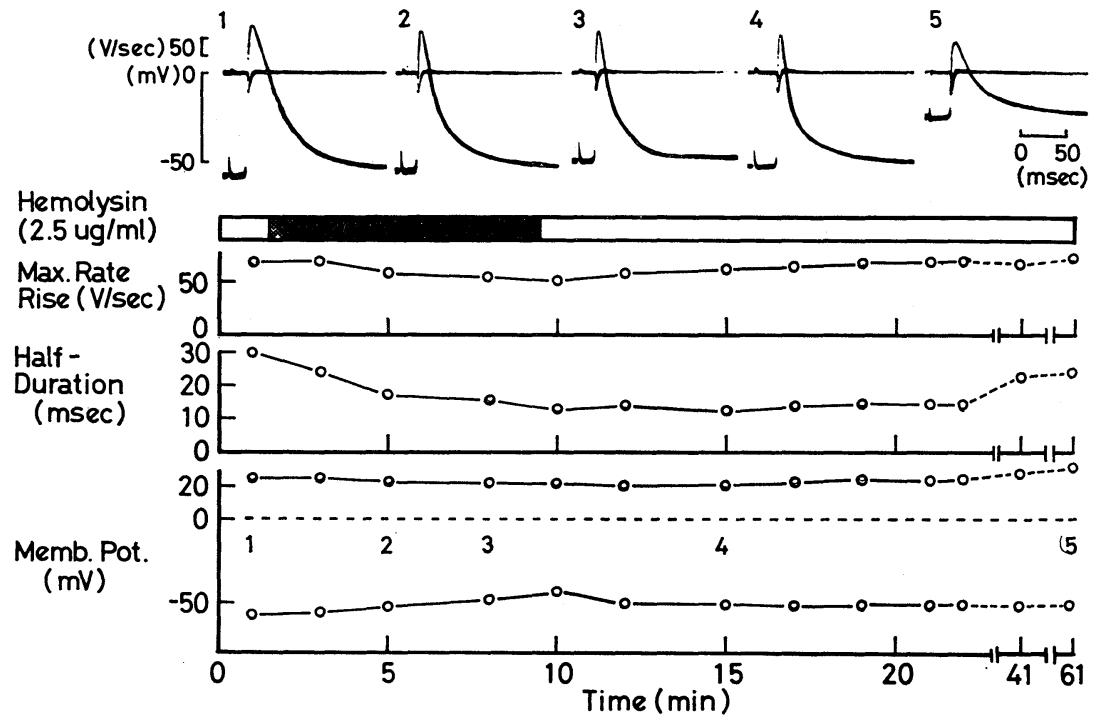

Fig. 3. Effect of hemolysin on the action potentials of atrial trabecula. The numerals in the upper row correspond to those in the bottom graph. The reference line indicates both zero membrane potential and maximum rate of rise of action potential. In the original tracing of panel 5 , the calibration for voltage should be read as $-100 \mathrm{mV}$. The application of hemolysin is indicated by the shaded area.

applied across the single sucrose gap in an atrial fiber (Fig. 5). When $30 \% \mathrm{Na}$ Tyrode solution was perfused, membrane was hyperpolarized by $8.6 \mathrm{mV}$ within $4 \mathrm{~min}$. Application of $10 \mu \mathrm{g} / \mathrm{ml}$ of hemolysin caused a gradual depolarization of the membrane by $8.6 \mathrm{mV}$, and the membrane was depolarized up to the original membrane potential. Depolarization of the membrane in response to $10 \mu \mathrm{g} / \mathrm{ml}$ of hemolysin was small during perfusion with $30 \% \mathrm{Na}$ Tyrode solution, whereas during perfusion with the control Tyrode solution, $10 \mu \mathrm{g} / \mathrm{ml}$ of hemolysin depolarized the resting membrane by a mean of $19 \mathrm{mV}$. After $8.1 \mathrm{~min}$ of perfusion with $30 \% \mathrm{Na}$ Tyrode solution with hemolysin, normal Tyrode solution was reintroduced. Transiently the membrane was depolarized further by $8.6 \mathrm{mV}$ and slope conductance was considerably reduced under this condition. These results suggest that the conductance to $\mathrm{Na}$ increases in response to hemolysin.

\section{Effect of tetrodotoxin on depolarization produced by hemolysin}

TTX, which has been known to specifically seal off the Na channel (NARAHASHI et al., 1964; NAKAMURA et al., 1965), is widely used to identify the Na channel. It was also shown that TTX antagonizes depolarization caused by several depolarizing agents, such as batrachotoxin (BTX), grayanotoxin (GTX) and veratridine (Albuquerque et al., 1973; Seyama and NARAhashi, 1973; Ohta et al., 1973). These agents are considered capable of increasing membrane conductance 


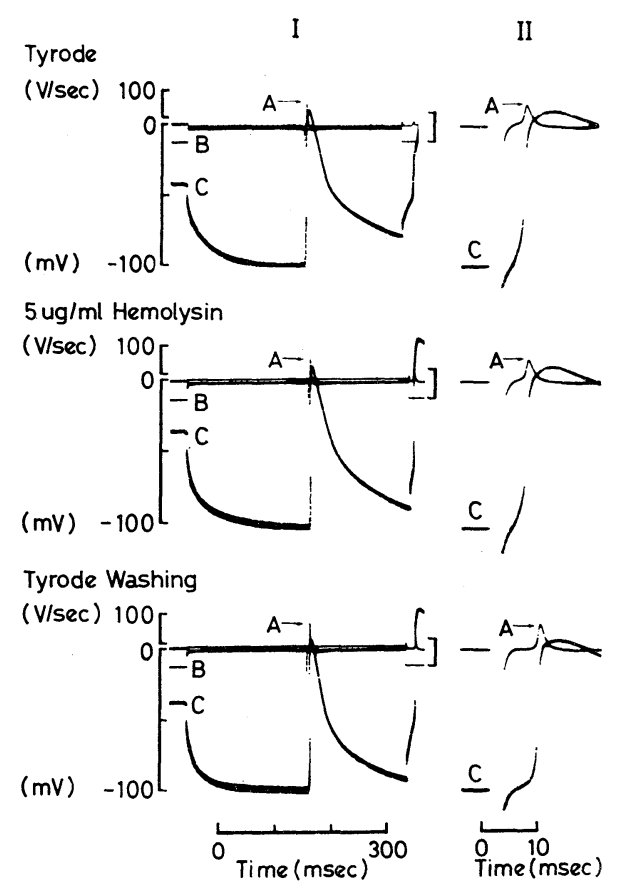

Fig. 4. Effect of hemolysin on the action potential generating mechanism. Maximum rate of rise of action potential (A), applied current intensity (B) and action potential (C) are shown in the slow speed record (column I) and the faster speed record (column II). To avoid complexity, line B's are not shown in column II. The vertical bars in between column I and II indicate $1 \times 10^{-4} \mathrm{~A}$. Control resting potential was low in this preparation for unknown reasons.

to Na. To further characterize the depolarization generated by hemolysin, TTX at a concentration of $1 \times 10^{-5} \mathrm{M}$ was applied during the action of hemolysin. This concentration of TTX was sufficient to inhibit the initial inward current in the myocardium (RougIER et al., 1969) and was 30 times greater than that for the antagonistic action of GTX effect in squid axon (SEYAma and Narahashi, 1973). Figure 6 shows that hemolysin-induced depolarization remained almost constant even after application of TTX. When the perfusate was switched to normal Tyrode solution, the membrane was slightly depolarized and then reverted to the original resting potential level in $30 \mathrm{~min}$. This observation is in good agreement with the finding of Fig. 5 where the membrane depolarized further with increasing $\left[\mathrm{Na}^{+}\right]_{0}$ from $43 \mathrm{~mm}$ to $143 \mathrm{~mm}$. As stated above, it has been reported that TTX antagonizes the depolarization induced by BTX, GTX, and veratridine, and hyperpolarized the membrane back to the original resting potential. However, in the present study, TTX decelerated a rate of development of the hemolysininduced depolarization but failed to reverse the membrane potential to the original 


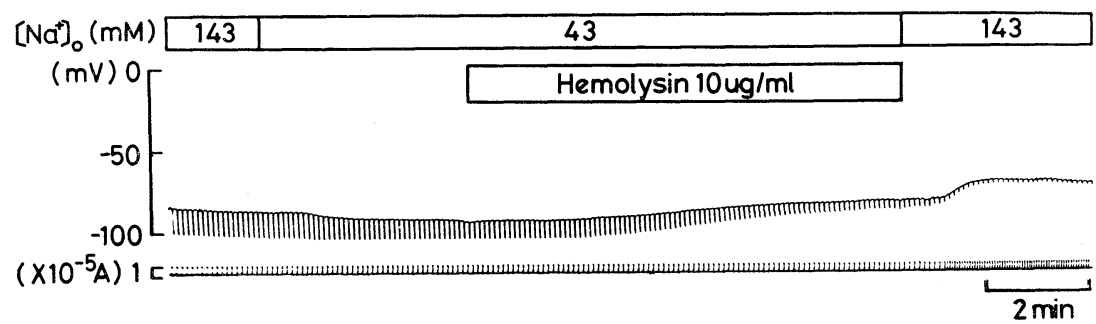

Fig. 5. Effect of hemolysin on the resting membrane potential and the membrane conductance of the atrium in $30 \% \mathrm{Na}$ solution.

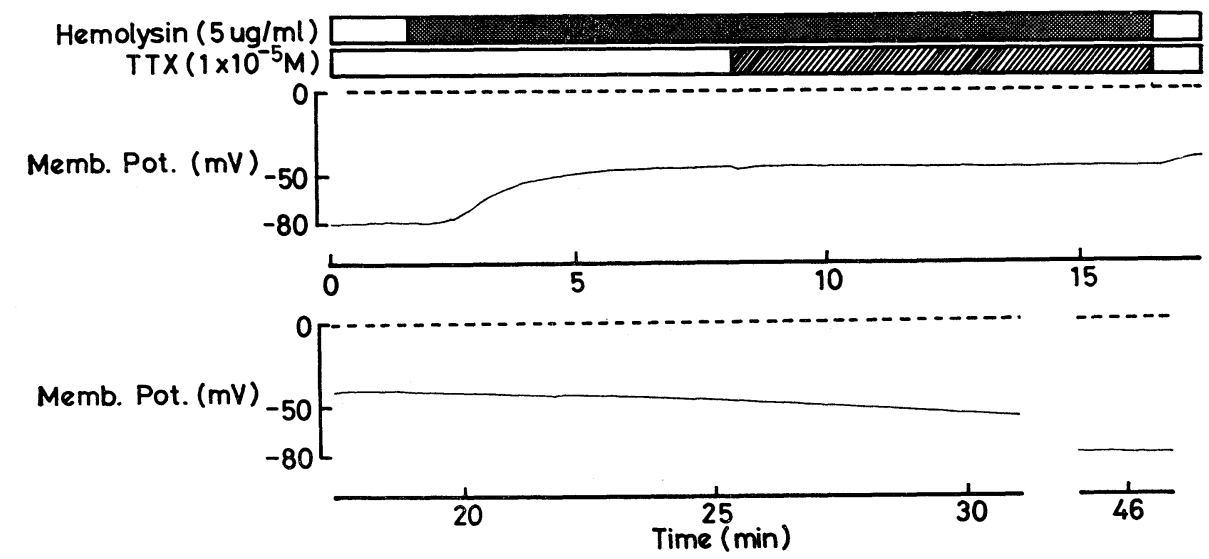

Fig. 6. Effect of TTX on the hemolysin-induced depolarization in the atrium. The application of hemolysin and TTX are indicated by the shaded and the hatched areas, respectively. Bottom row, indicating a change of membrane potential during wash out period, is continued from the top.

level. Hence, it is thought that the main action of hemolysin might be to increase membrane conductance to $\mathrm{Na}$ which may be insensitive to TTX.

\section{Dose-response curve for hemolysin on membrane resistance}

Since the membrane underwent an increase in permeability by hemolysin, one suitable indicator for this effect could be a measurement of membrane resistance. Successive application of hemolysin in increasing doses, from $2.5 \mu \mathrm{g} / \mathrm{ml}$ to $8 \mu \mathrm{g} / \mathrm{ml}$, produced a progressive reduction of the membrane resistance and depolarization of the resting membrane (Fig. 7). Although the delayed rectification might influence the change in membrane resistance at the depolarized membrane potential range, its proportion within the total membrane resistance change would be small except when the highest hemolysin concentration was employed. At this concentration, the membrane depolarized to around $-30 \mathrm{mV}$. In most mammalian heart muscle, it has been shown that the delayed rectification starts to 


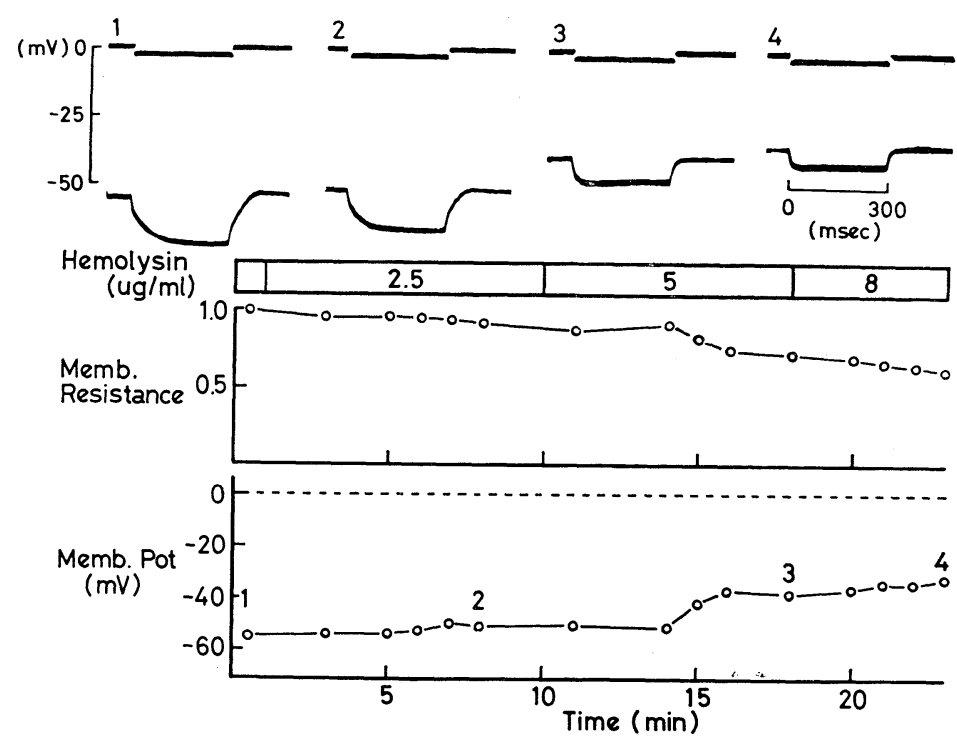

Fig. 7. Changes in the membrane resistance of atrial cell. In the top four panels, the upper traces indicate the anodal current, $5 \times 10^{-5} \mathrm{~A}$, and the lower traces show the membrane potential. The numerals in the top traces correspond to those in the bottom graph.

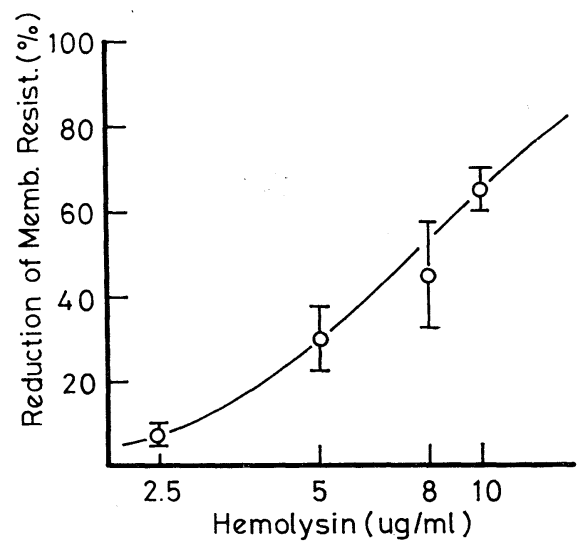

Fig. 8. Dose-response curve between concentration of hemolysin $(\mu \mathrm{g} / \mathrm{ml})$ and reduction of membrane resistance of the atrium. Open circles represent mean values and vertical bars S.D. of five experiments.

generate between -30 and $-10 \mathrm{mV}$ (Trautwein, 1973). Thus, the contribution of delayed rectification to the change of membrane resistance might be small. The relation between the concentration of hemolysin and the reduction of the membrane resistance is illustrated in Fig. 8. The concentration necessary to yield one-half maximum reduction of the membrane resistance was determined to be $7.5 \mu \mathrm{g} / \mathrm{ml}$. 


\section{Effect of hemolysin on the mechanical tension}

Hemolysin caused a positive inotropic action on the right atrial trabecular muscle (Fig. 9). Transient potentiation of the twitch tension was followed by a progressive increase in diastolic tension. With the elevation of diastolic tension, twitch tension gradually decreased. Diastolic tension continued to elevate for as long as $10-15$ min even after washing with normal Tyrode solution. As the twitch tension increased, the rate of rise of tension increased. Diastolic tension returned to the control level after 30 to $60 \mathrm{~min}$ of perfusion in normal Tyrode solution. Twitch tension in 3.5 and $5 \mu \mathrm{g} / \mathrm{ml}$ of hemolysin were 3.9 and 8.2 times greater than that in $2.5 \mu \mathrm{g} / \mathrm{ml}$ (average in five experiments). When more than $7 \mu \mathrm{g} / \mathrm{ml}$ of hemolysin was administered, a remarkable elevation in diastolic tension occurred, leading to muscle contracture (Fig. 10-2).

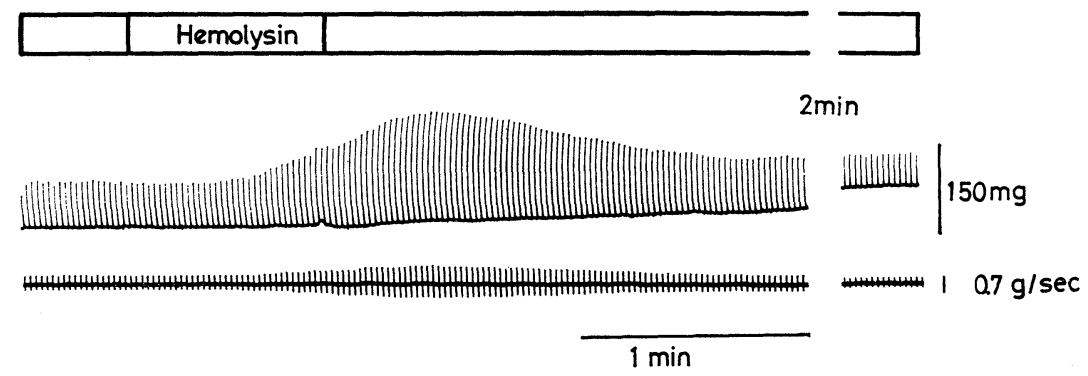

Fig. 9. Positive inotropic action of hemolysin on atrial fibers. Concentration of applied hemolysin was $2.5 \mu \mathrm{g} / \mathrm{ml}$. Upper record indicates the isometric tension. Lower record is the rate of rise of tension development.

\section{Contracture in response to $\mathrm{Na}$ depleted solution}

When $\left[\mathrm{Na}^{+}\right]_{0}$ was reduced, diastolic tension increased, resulting in contracture of the muscle (LÜTtGaU and Niedergerke, 1958; VASSORT, 1973; IrISAWA and NomA, 1976). This contracture was explained by an increase of intracellular $\mathrm{Ca}$ concentration, $\left[\mathrm{Ca}^{2+}\right]_{i}$, due to the Na-Ca exchange mechanism. The intracellular sodium concentration, $\left[\mathrm{Na}^{+}\right]_{\mathrm{i}}$, increased as a result of the increased membrane conductance during the action of hemolysin. When the concentration gradient for $\mathrm{Na}$ was reversed, i.e., from inside to outside, both $\mathrm{Na}$ efflux and $\mathrm{Ca}$ influx were enhanced (Reuter and Seitz, 1968; IrisawA and NomA, 1976). Figure 10 shows that $\left[\mathrm{Na}^{+}\right]_{\mathrm{i}}$ may increase after the administration of hemolysin. In Fig. 10-1, the right atrial trabecular muscle was perfused with $20 \% \mathrm{Na}$ Tyrode solution for control. Transient increase of twitch tension which was followed by an increase in diastolic tension was observed during $\mathrm{Na}$ depletion. On returning to the control Tyrode solution, a transient increase in twitch tension reappeared and then both twitch tension and diastolic tension were recovered. An application of $10 \mu \mathrm{g} / \mathrm{ml}$ of hemolysin induced a transient increase in twitch tension and a progressive increase in diastolic tension in the same preparation (Fig. 10-2). The contracture 


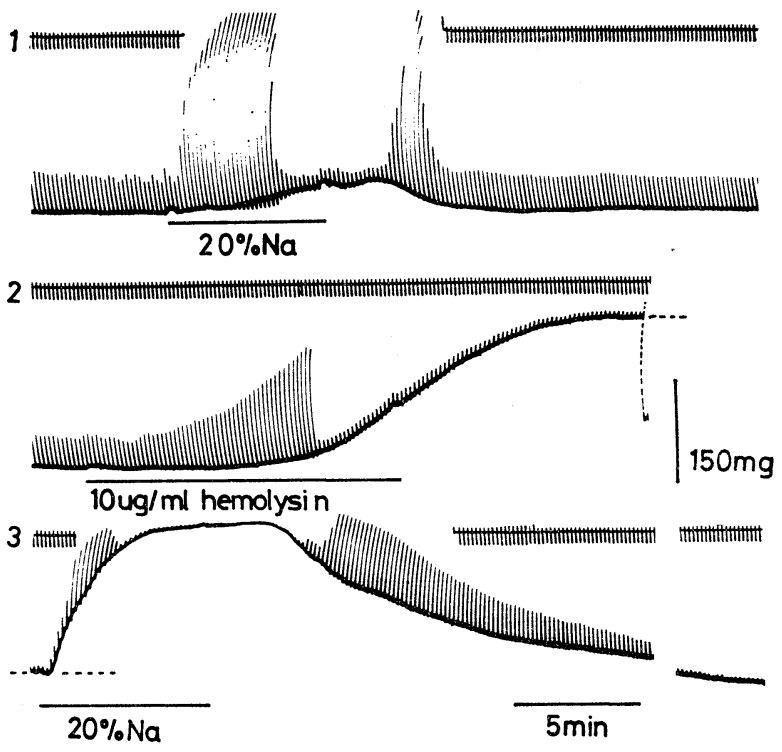

Fig. 10. Enhancement of the contracture tension by the low Na perfusion after the action of hemolysin. Panels 1, 2, and 3 are consecutive tracings. Panel 1 indicates the effect of the depletion of $\left[\mathrm{Na}^{+}\right]_{0}$ on the tension development. Panel 2 shows the effect of hemolysin within normal Tyrode solution. After the pretreatment of hemolysin (panel 2), further potentiation of the diastolic tension was observed during $\left[\mathrm{Na}^{+}\right]_{0}$ depletion. In panels 2 and 3 , dotted lines mean equivalent tension level. Since diastolic tension development almost reached the maximum level of the pen recorder after the action of hemolysin (panel 2), DC bias was added to cover further development of tension (panel 3).

obtained was approximately 5.5 times larger than that of the twitch tension. After reaching the maximal level of contracture, a $20 \% \mathrm{Na}$ Tyrode solution was reintroduced for $6.6 \mathrm{~min}$ (Fig. 10-3). With this procedure, the contracture tension increased still further.

Effect of propranolol on the tension development produced by hemolysin

There is a possibility that norepinephrine might have been liberated from the sympathetic nerve ending and increased the tension development of myocardium. To examine this possibility, the length-tension relationship in a normal Tyrode solution containing hemolysin was compared with that in a solution containing both hemolysin and propranolol $(1 \mathrm{mg} / \mathrm{ml})$ which is known to block the $\beta$-receptor (VAughan Williams, 1966). As shown in Fig. 11, there is essentially no change in both the active and passive tension development. Therefore, it is quite unlikely that the increased tension produced by hemolysin is due to the action of liberated norepinephrine. 


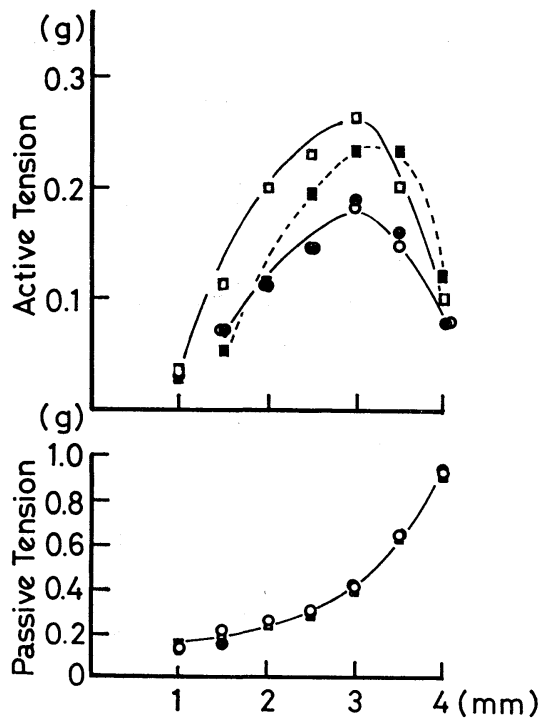

Fig. 11. Effect of propranolol on both the active and the passive tension development by hemolysin. $\bigcirc$ control, $\bullet$ propranolol $1 \mathrm{mg} / \mathrm{ml}, \square$ hemolysin $5 \mu \mathrm{g} / \mathrm{ml}$, $\square$ hemolysin $5 \mu \mathrm{g} / \mathrm{ml}$ +propranolol $1 \mathrm{mg} / \mathrm{ml}$. Ordinates mean active tension (upper graph) and passive tension (lower graph) in gram, respectively. Abscissa indicates the length of muscle strand.

\section{DISCUSSION}

Reduction in membrane resistance and depolarization of the membrane were the major responses to hemolysin in both S-A nodal and atrial cells, while hemolysin had no effect on action potential generating mechanisms. Since these phenomena were suppressed in low $\mathrm{Na}$ media and enhanced after reperfusing with normal Tyrode solution, they could be explained by assuming that hemolysin increased the membrane conductance to $\mathrm{Na}$. However, depolarization of the membrane induced by hemolysin was not reversed by the action of TTX, suggesting that either the channel responsible for the increase in conductance is insensitive to TTX or non-selective. The toxin may depolarize the membrane with an increase of $\mathrm{Na}$ influx and result in an increase of $\left[\mathrm{Na}^{+}\right]_{i}$. This mechanism could be the cause of both potentiation of twitch tension (Fig. 9) and enhancement of contracture (Fig. 10-2 and -3) induced by hemolysin. The potentiation of twitch tension observed at a low concentration of hemolysin might be induced by the competitive action of increased $\left[\mathrm{Na}^{+}\right]_{i}$ to the $\mathrm{Ca}$ binding site (PALMER and PoseY, 1967), resulting in an increase in $\left[\mathrm{Ca}^{2+}\right]_{\mathrm{i}}$. The enhancement of contracture at a higher concentration of hemolysin may also be explained by the hemolysininduced increase of $\left[\mathrm{Na}^{+}\right]_{\mathrm{i}}$. Withdrawal of $\mathrm{Na}$ from external medium would have intensified the efflux of $\mathrm{Na}^{+}$and in turn the influx of $\mathrm{Ca}^{2+}$ via $\mathrm{Na}-\mathrm{Ca}$ ex- 
change mechanism, leading to increase in $\left[\mathrm{Ca}^{2+}\right]_{\mathrm{i}}$ (Fig. 10-3). The effective doses of hemolysin necessary to stop the spontaneous beating of the isolated cultured myocardial cells was $0.2 \mu \mathrm{g} / \mathrm{ml}$ (GosHima et al., 1976), and was smaller than that observed in the present study $(1 \mu \mathrm{g} / \mathrm{ml})$. These differences in sensitivity may come from a reduction of effective hemolysin concentration due to the absorption onto the connective tissue or from species difference.

It is worthwhile to point out the similarities of the mode of action of hemolysin to those of other substances known to cause depolarization in the myocardial membrane. The constituents of veratrum alkaloid have been reported to exert a depolarizing action on the ventricular myocardium and Purkinje fibers, producing tachycardia and prolongation of the action potential duration (TRAUTWEIN, 1963). Batrachotoxin, steroidal alkaloid, has been shown to depolarize Purkinje fibers irreversibly due to an increase of $\mathrm{Na}$ conductance, without disturbing the action potential generating mechanism (HogAN and AlbuQUERQUe, 1971). Aconitine, an alkaloid from Aconitum napellus L., also caused depolarization of the ventricular myocardium and Purkinje fiber, most probably due to increasing the $\mathrm{Na}$ permeability. All these substances are small molecules with molecular weights of several hundreds. On the other hand, hemolysin is a macromolecule, with a molecular weight of 42,000 (HoNDA et al., 1976b). There is evidence suggesting that the site of action of veratrum alkaloid and GTX is located inside the membrane (Meves, 1966; Narahashi and Seyama, 1974). It is unlikely that the macromolecule of hemolysin could pass the membrane in a form of native protein molecule. Therefore, the site of action of hemolysin might be located on the outer surface of the membrane. However, there remains a possibility that this toxin might have an action similar to cholera toxin. Cholera toxin is known to bind the receptor site on the membrane, and the bound material behaves as an integral membrane protein. It has been reported that with a certain time lag, an "active" subunit of cholera toxin could be translocated within the cell membrane (SAhyoun and Cuatrecasas, 1975).

This work was supported by research grants from the Ministry of Education, Science and Culture of Japan, the Japan Heart Foundation and the Japan Society for the Promotion of Science.

\section{REFERENCES}

Albuquerque, E. X., Seyama, I., and Narahashi, T. (1973) Characterization of batrachotoxininduced depolarization of the squid giant axons. J. Pharmacol. Exp. Ther., 184: 308-314.

Goshima, K., Honda, T., Hirata, M., Kikuchi, K., Takeda, Y., and Miwatani, T. (1976) Stopping of spontaneous beating of myocardial cells in vitro by a toxin from Vibrio parahaemolyticus. J. Cell. Mol. Cardiol., in press.

Goto, M., SaKamoto, Y., and Imanaga, I. (1967) Aconitine-induced fibrillation of the different muscle tissues of the heart and the action of acetylcholine. In: Electrophysiology and Ultrastructure of the Heart, ed. by Sano, T., MizuHira, V., and Matsuda, K. Bunkodo, Tokyo. 
Hogan, P. M. and Albuquerque, E. X. (1971) The pharmacology of batrachotoxin. III. Effect on the heart Purkinje fibers. J. Pharmacol. Exp. Ther., 176: 529-537.

Honda, T., Goshima, K., Takeda, Y., Sugino, Y., and Miwatani, T. (1976a) Demonstration of the cardiotoxicity of the thermostable direct hemolysin (lethal toxin) produced by Vibrio parahaemolyticus. Infect. Immunol., 13: 163-171.

Honda, T., Taga, S., Takeda, T., Hasibuan, M. A., Takeda, Y., and Miwatani, T. (1976b) Identification of lethal toxin with the thermostable direct hemolysin produced by Vibrio parahaemolyticus and some physiological properties of the purified toxin. Infect. Immunol., 13: 133-139.

IRISAWA, H. and NomA, A. (1976) Contracture and hyperpolarization of the rabbit sinoatrial node cells in Na-depleted solution. Jap. J. Physiol., 26: 133-144.

Lüttgau, H. C. and Niedergerke, R. (1958) The antagonism between $\mathrm{Ca}$ and $\mathrm{Na}$ ions on the frog's heart. J. Physiol., 143: 486-505.

Meves, H. (1966) The effect of veratridine on internally perfused giant axons. Pflügers Arch., 290: 211-217.

Nakamura, Y., NAKaJima, S., and Grundfest, H. (1965) The action of tetrodotoxin on electrogenic components of squid giant axons. J. Gen. Physiol., 48: 985-996.

Narahashi, T. (1974) Chemicals as tools in the study of excitable membranes. Physiol. Rev., 54: $813-889$.

Narahashi, T., Moore, J. W., and Scott, W. R. (1964) Tetrodotoxin blockage of sodium conductance increase in lobster giant axons. J. Gen. Physiol., 47: 965-974.

NARAHAShi, T. and SeyAmA, I. (1974) Mechanism of nerve membrane depolarization caused by grayanotoxin I. J. Physiol., 242: 471-487.

Noma, A. and Irisawa, H. (1974) The effect of sodium ion on the initial phase of the sinoatrial pacemaker action potentials in rabbits. Jap. J. Physiol., 24: 617-632.

Ohta, M., Narahashi, T., and Keeler, R. F. (1973) Membrane potential and conductance of squid and crayfish giant axons. J. Pharmacol. Exp. Ther., 184: 143-154.

PAlmer, R. F. and Posey, V. A. (1967) Ionic effects on calcium accumulation by cardiac sarcoplasmic reticulum. J. Gen. Physiol., 50: 2085-2095.

Reuter, H. and SeItz, N. (1968) The dependence of calcium efflux from cardiac muscle on temperature and external ion composition. J. Physiol., 195: 451-470.

Rougier, O., Vassort, G., Garnier, D., Gargouil, Y. M., and Coraboeuf, E. (1969) Existence and role of a slow inward current during the frog atrial potential. Pflügers Arch., 308: $91-110$.

Sahyoun, N. and CuAtrecasas, P. (1975) Mechanism of activation of adenylate cyclase by cholera toxin. Proc. Nat. Acad. Sci. USA, 72: 3438-3442.

Seyama, I. (1976) Characteristics of the rectifying properties of the sino-atrial node cell of the rabbit. J. Physiol., 255: 379-397.

SEYAMA, I. and NARAHASHI, T. (1973) Increase in sodium permeability of squid giant axon membrane by $\alpha$-dihydrograyanotoxin II. J. Pharmacol. Exp. Ther., 184: 299-307.

TrautweIn, W. (1963) Generation and conduction of impulses in the heart as affected by drugs. Pharmacol. Rev., 15: 277-332.

Trautwein, W. (1973) Membrane currents in cardiac muscle fibers. Physiol. Rev., 53: 793835.

UlbRicht, W. (1969) The effect of veratridine on excitable membranes of nerve and muscle. Ergeb. Physiol., 61 : 17-71.

VASSORT, G. (1973) Influence of sodium ions on the regulation of frog myocardial contractility. Pflügers Arch., 339: 225-240.

Vaughan Williams, E. M. (1966). Mode of action of betareceptor antagonists on cardiac muscle. Am. J. Cardiol., 18: 399-405. 